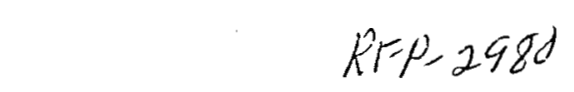

CONF-800402--2

\title{
EQUILIBRIA AND THERMODYNAMIC PROPERTIES \\ OF THE PLUTONIUM-HYDROGEN SYSTEM
}

John M. Haschke

Angelo E. Hodges, III

C. Michael Smith

Franklin L. Oetting

\author{
ROCKWELL INTERNATIONAL \\ ENERGY SYSTEMS GROUP \\ ROCKY FLATS PLANT \\ P. 0. BOX 464 \\ GOLDEN, COLORADO 80401
}

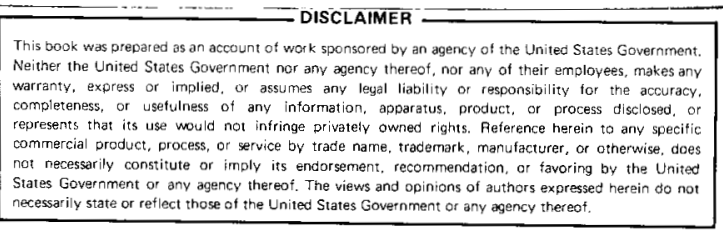




\section{DISCLAIMER}

This report was prepared as an account of work sponsored by an agency of the United States Government. Neither the United States Government nor any agency Thereof, nor any of their employees, makes any warranty, express or implied, or assumes any legal liability or responsibility for the accuracy, completeness, or usefulness of any information, apparatus, product, or process disclosed, or represents that its use would not infringe privately owned rights. Reference herein to any specific commercial product, process, or service by trade name, trademark, manufacturer, or otherwise does not necessarily constitute or imply its endorsement, recommendation, or favoring by the United States Government or any agency thereof. The views and opinions of authors expressed herein do not necessarily state or reflect those of the United States Government or any agency thereof. 


\section{DISCLAIMER}

Portions of this document may be illegible in electronic image products. Images are produced from the best available original document. 


\section{ABSTRACT}

Equilibrium, kinetic and $X$-ray diffraction data show the existance of two stability regians in the $\mathrm{Pu}-\mathrm{H}$ system. A metastable solid solution between $\mathrm{CaF}_{2}$-type $\mathrm{PuH}_{1.9}$ and anti-Fe ${ }_{3} \mathrm{Al}$-type $\mathrm{PuH}_{3.0}$ forms at low temperature and behaves as an ideal solid solution. Equilibrium and calorimetric results show that the enthalpy of formation varies linearly from -38 to $-50 \mathrm{kcal} / \mathrm{mol}$ between the lower phase boundary and the trihydride. The phase relationships established at high temperature are similar to those of the lanthanide difluoridelanthanide trifluoride systems. A series of $\mathrm{CaF}_{2}$-related phases apparently forms between $\mathrm{PuH}_{1.9}$ and $\mathrm{PuH}_{2} .5$; a nonstoichiometric hexagonal (LaF -type) $^{- \text {a }}$ hydride exists in the range $\mathrm{PuH}_{2} .9^{-} \mathrm{PuH}_{3} .0$. A procedure for preparing pure hexagonal $\mathrm{PuH}_{3.00}$ is described and the hysteresis behavior of the $\mathrm{Pu}-\mathrm{H}$ system is discussed.

\section{INTRODIJCTION}

The formation of plutonium hydride is a facile reaction which finds application in plutonium recovery procedures and in powder metallurgy. As noted in a recent report on the decomposition kinetics of plutonium hydride, many fundamental properties of importance to these applications are poorly defined. [1]

Various physicochemical properties which have been described for the $\mathrm{Pu}-\mathrm{H}$ system include phase equilibria [2-4], structural properties [5,6], reaction kinetics [1,7-9] and thermodynamic properties.[1-3,10-12] These studies have shown that $\mathrm{Pu}$ and $\mathrm{H}_{2}$ form a $\mathrm{CaF}_{2}$-type dihydride, a cubic hydride, $\mathrm{PuH}_{\mathrm{X}}$, of variable composition with $2 \leqslant x \leqslant 3$, and a hexagonal trihydride. Diffraction data show that the solid solution obeys Vegard's 1 aw for $2.0<x<2.5 \cdot[3,6]$ For $X>2.5$, the cubic parameter is invariant, but a second phase is not observed. [6] Although the formation of a hexagonal phase is documented [4], neither the 
conditions for its preparation nor its phase relationship with the cubic hydride is defined. Discrepencies in the enthalpy of formation of the hydride have recently been reviewed. [12] In addition, hysteresis loops are observed at high hydride compositions [4], and marked differences in the reactivities of hydrides prepared at different temperatures are reported. [7] The present report is a result of a continuing effort to clarify the equilibria and thermochemistry of the Pu-H system using a variety of experimental techniques.

\section{EXPERIMENTAL PROCEDURES}

Plutonium metal ( 0.13 wt \% impurity) stabilized in the delta phase by 1.0 wt \% Ga and ultra-high purity hydrogen (Matheson) were used in all tests. Since earlier work has shown that the hydrides of alpha and delta metal behave identically, Ga was treated as an inert component. In all experiments at $P<500$ torr, pure $\mathrm{H}_{2}$ was generated by thermal decomposition of $\mathrm{UH}_{3}$.

Low pressure $T X$ isobars $(1.0,3.2,10.0,31.6,100,316$ torr) were obtained over the composition range $2.0 \leq X \leq 2.9$ by microbalance methods. [1] $\mathrm{H}_{2}$ pressures were fixed by thermal control of the $\mathrm{U}-\mathrm{UH}_{3}$ purifier; the temperature range $\left(25-500^{\circ} \mathrm{C}\right)$ was scanned at a linear rate of $2 \% \mathrm{~min}$. Hydriding rates and equilibrium data of higher pressure $\mathrm{H}$-rich (initial $\mathrm{H}: \mathrm{Pu}$ ratio $>3$ ) systems were measured by PVT methods. During the rate studies, heat loss by the reactants was retarded by containment of the $25 \mathrm{~g}$ Pu sample in a silica cup; temperature and pressure data were recorded with an acquisition system. X-Riay data were obtained with a powder diffractometer. $P_{u H_{x}}$ samples $(0.05-0.08 \mathrm{~g})$ for solution (6MHC1) calorimetric determinations of the enthalpy of formation were prepared using a high temperature vacuum procedure and were analyzed by microbalance methods. [1] 
4. RESULTS AND DISCUSSION

\subsection{The Cubic Solid Solution.}

4.11 Equilibria. Microbalance data for the low pressure regime (1.0-316 torr) show the existence of linear TX isobars over the composition range 2.0 $\leq x \leq 2.9$. Non-linearity. from hysteresis behavior similar to that described by Mulford and Sturdy [4] was observed at low temperatures and high pressures with the initial hydride prepared from the bulk metal. Hysteresis was not observed with subsequent hydrides prepared from powdered metal formed by thermal decomposition of hydride. X-Ray diffraction data for $\mathrm{PuH}_{\mathrm{X}}$ samples in the range $2.0 \leq x \leq 2.8$ showed only the cubic phase. The accuracy of the isobars obtained by scanning TX space at $2^{\circ} / \mathrm{min}$ was verified at several constant temperatures; in all cases the differences in $X$ from the two techniques were less than 0.01 . This observation and the results of similar tests to determine the response of $X$ to pressure changes at constant $T$ demonstrate that the reaction rate and hydrogen transport rates of $\mathrm{PuH}_{\mathrm{x}}$ are rapid.

As demonstrated by the graphs of $\log P\left(H_{2}\right)$ at specific $X$ values vs $1 / T$ in Fig. 1, the vapor pressure of the cubic hydride changes continuously over the range $1.9<x<3.0$. Hystereis effects are excluded from the data. The dashed line describes the equilibrium vapor pressure in the two-phase region $0<X<1.90 \pm 0.05$. [1] The constants obtained by linear $(\log P=A-B / T)$ leastsquares refinement of the data are listed with the respective graphs in Fig. 1. The average intercept for $x=1.9$ and for all compositions in the range $2.2 \leq x \leq 2.8$ is $9.81 \pm 0.16$. Slope values for $x=2.0,2.2$ and 2.9 have been calculated from the average intercept and single pressure values. Since the average slope change per 0.1 change in $X$ is $550 \pm 1.40$, the estimated pressure equation for cubic $\mathrm{PuH}_{3.0}$ is defined by $A=9.81$ and $B=1650$. 
The results in Fig. 1 support the conclusions of earlier workers $[2,4]$ that the cubic hydride behaves as a solid solution formed by occupancy of octahedral sites in the $\mathrm{CaF}_{2}$-type dihydride. The results also suggest that the solution is nearly ideal. The family of curves in Fig. 1 have the characteristic features of a Cox chart, a $\log P$ vs $1 / T$ graph used to correlate vapor pressure data for organic liquids forming ideal solutions. [13] In organic systems, a common intercept and "wagon wheel" behavior of the pressure curves is observed as the solution composition changes. Since similar behavior is evident in Fig. 1, cubic PuHx apparently behaves as an ideal solid solution over the range $1.9 \leq x \leq 3.0$; i.e., the hydride structure gradually changes from a defect $\mathrm{CaF}_{2}$-type phase to an anti-Fe $\mathrm{F}_{3} \mathrm{Al}$-type phase as $\mathrm{X}$ increases.

4.12 Hysteresis. The present observations provide new insight into the hysteresis phenomenon. Loops in TX isobars for the initial hydrides resulted from the fact that higher $X$ values were observed on ascending $T$ than on descending $T$ for $x>2.6$. At lower $x$, equilibrium points were reproducible in both directions and generated a linear isobar that was reproducible at all $X$ values (1) on decending $T,(2)$ on all subsequent thermal cycles with a given sample, and (3) for all hydrides prepared from thermally dehydrided metal. As noted by Mulford and Sturdy [4], the size of the loop increased with increasing $\mathrm{H}_{2}$ pressure; $\Delta T$ values across the loops at 1,10 and 100 torr were $11^{\circ}, 20^{\circ}$ and $38^{\circ}$, respectively. The presence of hexagonal hydride was detected in earlier work with hysteresis samples [4], but only the cubic phase was observed in the present study.

Additional experiments to characterize the hysteresis phenomenon included controlled rehydriding tests and a thermal scan of the loop. Since the hydriding rate of dehydrided metal powder was faster than that of bulk metal and produced 
a thermal spike which could easily self-heat the sample beyond the hysteresis range, several samples were rehydrided slowly at low pressures. Hysteresis could not be induced. In an attempt to scan the 10 torr loop, the temperature was repeatedly increased to $120^{\circ} \mathrm{C}\left(50^{\circ}\right.$ below the closure point of the lqop) and decreased to $25^{\circ} \mathrm{C}$. The initial TX behavior was not reproducible on cycling; measured points decayed rapidly and were coincident with the linear isobar during descent of the second cycle.

Our observations suggest that the hysteresis results from the presence of a thermally unstable contaminant in the bulk metal. A reasonable candidate is hydroxide, which would readily substitute for hydride in the lattice, would be destroyed by high temperature and would be absent during rehydriding. Since $\mathrm{H}_{2}$ and $\mathrm{PuO}_{2}$ are the anticipated products of thermal decomposition, an increase in $\mathrm{H}_{2}$ pressure should stabilize hydroxide and increase the loop size.

\subsection{Thermodynamic Properties. The variation of the enthalpy of formation of} the hydride across the composition range of cubic $\mathrm{PuH}_{\mathrm{x}}$ has been determined both from equilibrium and calorimetric data. Enthalpy values were obtained by GibbsDuhem integration of the pressure data in Fig. 1. The respective $\Delta H_{f}^{o}$ values for $\mathrm{PuH}_{X}$ at $X=1.9,2.5$ and 3.0 are $(-37.3 \pm 0.5),(-45.9 \pm 0.8)$ and $(-49.6 \pm 0.8) \mathrm{kcal} / \mathrm{mol}$. Calorimetric results based on multiple measurements of the enthalpies of solution of delta-stabilized metal and cubic $\mathrm{PuH}_{\mathrm{x}}$ samples in $6 \mathrm{MHCl}$ give $\Delta \mathrm{R}_{\text {soln }}^{\circ}$ $(\delta-\mathrm{Pu}, \mathrm{s})=(-140.81 \pm 0.55) \mathrm{kcal} / \mathrm{mol}, \Delta \mathrm{H}_{\text {soln }}^{\circ}\left(\mathrm{PuH}_{2.21}, \mathrm{~s}\right)=(-98.27 \pm 0.39) \mathrm{kcal} / \mathrm{mol}$ and $\Delta H_{\text {soln }}^{\circ}\left(\mathrm{PuH}_{2} .62, \mathrm{~s}\right)=(-93.52 \pm 0.62) \mathrm{kcal} / \mathrm{mol}$ and yield the following enthalpies of formation: $\Delta H_{\mathrm{f} 298}^{\circ}\left(\mathrm{PuH}_{2.21}\right)=(-42.54 \pm 0.34) \mathrm{kcal} / \mathrm{mol}$ and $\Delta H_{\mathrm{f} 298}^{\circ}\left(\mathrm{PuH}_{2.62}\right)=$ $(-47.29 \pm 0.50) \mathrm{kcal} / \mathrm{mol}$.

The thermodynamic results obtained by the two techniques are in excellent agreement and indicate that the enthalpy of formation of the hydride varies 
linearly with $X$ from $(-38 \pm 1) \mathrm{kcal} / \mathrm{mol}$ at $\mathrm{PuH}_{1.9}$ to $(-50 \pm 1) \mathrm{kcal} / \mathrm{mol}$ at $\mathrm{PuH}_{3.0}$. The phase boundary value is in excellent agreement with the second-law result of Mulford and Sturdy [3], and those in the miscibillity range are in good agreement with previous measurements [12] if probable uncertainties in $X$ are considered. The linear change in $\Delta H_{f}^{\circ}$ with $X$ confirms the conclusion that behavior of the cubic solid solution is ideal.

\subsection{The Ordered Hydrides}

4.21 Preparation of Hexagonal Trihydride. Samples of stoichiometric plutonium trihydride, $\mathrm{PuH}_{3.00 \pm 0.01}$, have been reproducibly obtained by rapid reaction of $25 \mathrm{~g}$ samples of delta-phase plutonium in the presence of an excess $\mathrm{H}_{2}$ concentration of $0.06 \mathrm{~mol} / \mathrm{l}$. Products from preliminary tests in which the metal was in direct contact with the stainless steel reactor were found to contain hexagonal hydride, but PVT data showed that the bulk composition was approximately $\mathrm{PuH}_{2.8}$. The reaction was successful when the metal was insulated by containment in a silica cup so that the sample temperature exceeded $400^{\circ} \mathrm{C}$ for several minutes. PuH $\mathrm{P}_{3.00}$ was produced by cooling the sample in the residual $\mathrm{H}_{2}$ $\left(1.4 \mathrm{~atm}\right.$ at $\left.25^{\circ} \mathrm{C}\right)$

4.22 Equilibria. Results of kinetic, $X$-ray diffraction and PVT measurements show that an ideal solid solution is not formed in the Pu-H system at the conditions used for preparing hexagonal trihydride. Rates of hydrogen consumption, $R$, for a typical hydriding reaction are graphed on a logarithmic scale as a function of bulk composition in Fig. 2. Interesting variations in the rate are evident. In the metal-hydride two-phase region not shown, enR increases linearly from negative values to a maximum of 7.0 near $x=1.0$ and then decreases to a minimum at $X=1.90$. As shown in Fig. 2, $R$ increases for $1.90<X<2.00$, decreases in the range $2.00<x<2.20$, and is essentially constant for $2.20<x<2.45$. A 
small increase in $R$ near $X=2.45$ is followed by a steady decline to $X=2.85$ and a second decline for $2.85<x<3.00$. As shown by the elapsed time (upper abscissa), the initial reaction is rapid and the $X=2.85$ composition is reached after approximately $7 \mathrm{~min}$; an additional hour is required for $x$ to reach 3.00 .

The validity of the rate measurements is reflected by the gas phase temperature in Fig. 2. This temperature profile and that (not shown) of the solid sample closely track the kinetic results. The relative magnitudes of the exotherms accompanying the rate increases near $x=2.00$ and 2.45 are particularly interesting. Although the changes in $X$ are similar (1.90-2.20 vs $2.45-2.85)$ the area of the second peak is 5-6 times larger than that of the first. The appearance of this large exotherm is characteristic of reactions in which hexagonal hydride is formed.

Several properties of the hexagonal product are also different from those of the cubic hydride. Cubic products formed by slow (low sample temperature) reaction are finely divided powders which readily ignite in air at $25^{\circ} \mathrm{C}$. The products of rapid (high temperature) reaction are primarily composed of large (cm-sized) hydride particles and are less pyrophoric than the cubic products. Temperatures of $200-300^{\circ} \mathrm{C}$ are frequently required for ignition in air. Thermal decomposition of a single 0.5 g hydride particle on a microbalance showed a bulk composition of $X=(2.80 \pm 0.05)$ for the sample in vacuum at $25^{\circ} \mathrm{C}$. On heating at $2 \% / \mathrm{min}, \mathrm{H}_{2}$ loss was detected at $150^{\circ} \mathrm{C}$ and occurred in four distinct steps in the composition ranges $2.80>x>2.45$, $2.45>x>2.25,2.25>x>1.90$ and $1.90>x>0$. The behavior in the lower composition regions is similar to that of cubic $\mathrm{PuH}_{x}$, but the decomposition rate of the sample at 2.80 is much slower than that of the cubic phase at the same composition. [1] 
The formation of hexagonal hydride has been verified by X-ray diffraction analysis of two samples from a $\mathrm{PuH}_{3.00}$ product which had been stored in air (low $t_{2}$ pressure) for several days. Analysis of fine powder showed approximately $10 \%$ hexagonal and $30 \%$ cubic phase. The surface of a large particle showed only the cubic phase. After the same particle had been crushed, re-analysis showed greater than $90 \%$ hexagonal phase. The lattice parameter of the $\mathrm{CaF}_{2}$-type hydride, $(5.341 \pm 0.003) \AA$, is in excellent agreement with the value reported for PuHz.5. [4-6] The lattice parameters of the coexisting substoichiometric (see below) hydride, $\mathrm{PuH}_{3-z}$, are $a=(3.779 \pm 0.005)$ and $\underline{c}=(6.771 \pm 0.008) \AA$. The data indicate that the phase has the disordered $\mathrm{LaF}_{3}$-type $\left(\mathrm{PG}_{3} / \mathrm{mmc}\right)$ structure. [14] Superstructure reflections characteristic of an ordered LaF $_{3}$-type $(P 3 \mathrm{Cl})$ structure or of a phase with ordered anion vacancies are not observed. PVT equilibrium measurements with a sample of $\mathrm{PuH}_{3.00}$ demonstrate that the hexagonal hydride is nonstoichiometric. A PX isotherm at $125^{\circ} \mathrm{C}$ shows that the equilibrium pressure decreases exponentially from $9.6 \mathrm{~atm}$ at $\mathrm{PuH}_{3.00}$ to $0.014 \mathrm{~atm}$ at $\mathrm{Puth}_{2.89}$ and remains constant at lower compositions. Although the existence of a two-phase region below $X=2.89$ is established, the composition of the second phase has not been determined by equilibrium measurements. A partial isotherm at $25^{\circ} \mathrm{C}$ shows that the equilibrium pressure of $\mathrm{PuH}_{3.00}$ is $0.030 \mathrm{~atm}$, but the data are insufficient for evaluation of thermodynamic values.

Kinetic, structural and equilibrium data indicate that the $\mathrm{Pu}-\mathrm{H}$ system enters an ordered regime at moderate pressures and temperatures above $350-400^{\circ} \mathrm{C}$. The existence of a substoichiometric hexagonal hydride, $\mathrm{PuH}_{3-\mathrm{z}}$, and a twophase region is certain, but the behavior of the system at lower compositions remains somewhat unclear. The kinetic results indicate that the hydride 
system is closely modeled by lanthanide fluoride systems. Recent structural studies of the $M F_{2}-M F_{3}$ systems of $S m, E u$, and $Y b$ show that a series of ordered $\mathrm{CaF}_{2}$-related phases exist between the $\mathrm{CaF}_{2}$-type difluorides and the $\mathrm{LaF}_{3^{-}}$-

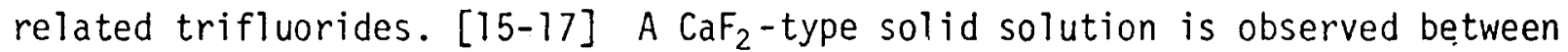
$\mathrm{MF}_{2.00}$ and $\mathrm{MF}_{2.20}$; stoichiometric phases include tetragonal $\mathrm{M}_{3} \mathrm{~F}_{7}(\mathrm{X}=2.333)$, rhombohedral $\mathrm{M}_{14} \mathrm{~F}_{33}(X=2.357)$, and cubic $\mathrm{M}_{27} \mathrm{~F}_{64}(\mathrm{X}=2.370)$. A rhombohedral solid solution forms between $M_{13} F_{31}(X=2.385)$. and $M_{13} F_{32}(X=2.462)$, and a twophase region exists between $\mathrm{MF}_{2.46}$ and $\mathrm{MF}_{3}$. The correspondence of the rate profile and the fluoride phase diagram in Fig. 2 is remarkable.

If one accepts the conclusion that different plutonium hydride phases react with hydrogen at slightly different rates, there is little doubt that hydride and fluoride systems are similar. Since the known lower hydride phase boundary at $X=1.9 \quad[1,3,12]$, the existence of the $\mathrm{PuH}_{2.45}-\mathrm{PuH}_{2.89}$ two-phase region, and the formation of a substoichiometric trihydride are accurately. predicted by the rate results, it is reasonable to assume that the rate profile is applicable at intermediate compositions. The rate increase between $X=1.9$ and 2.0 is attributed to the filling of vacant tetrahedral sites in $\mathrm{PuH}_{2+z}$. For the test in Fig. 2, a constant rate is observed over the range of the $\mathrm{CaF}_{2}$-related phases; however, in some tests small rate and thermal spikes occur between $X=2.20$ and 2.35 , an anticipated two-phase region. It should be noted that the $X=(2.85 \pm 0.05)$ boundary for $\mathrm{PuH}_{3-z}$ has been established by examining gas phase cooling curves (en $\Delta \mathrm{T}$ vs time) to determine the time and corresponding $X$ value at which the rapid exothermic process stopped.

Insight into the origin of the hysteresis phenomenon is gained by comparison of the equilibrium data for the cubic and hexagonal hydrides. At $125^{\circ} \mathrm{C}$ and $0.014 \mathrm{~atm}(\log P=1$ in Fig. 1), the composition of the cubic phase is 
fixed at $\mathrm{PuH}_{2.66}$. At this PT condition the presence of the hexagonal phase confines the composition to the two-phase region $2.45<x<2.89$. The exact value of $X$ depends on the molar ratio of cubic and hexagonal products. The reproducible hysteresis composition at $25^{\circ} \mathrm{C}$ and $0.014 \mathrm{~atm}$ is $X=2.69$. Although earlier workers have attributed the hysteresis to the presence of the hexagonal phase [4], the identical mole fraction of hexagonal phase must form in every hydride product in order for the loop to be reproducible. This possibility seems rather remote.

Careful structural and equilibrium studies are needed for complete definition of the phase relationships in the range $2.00<x<2.45$. The potential for success of such work has been strengthened by recent results for the hydrides of $\mathrm{La}, \mathrm{Ce}, \mathrm{Pr}$ and $\mathrm{Nd}$. Although earlier work had shown the existence of $\mathrm{MH}_{\mathrm{x}}$ solid solutions for $1.9<X<3.0$ [18], re-examination of these systems has shown obedience to Vegard's law in the range $2.0<x<2.5$. [19] Recent high resolution diffraction studies on the $\operatorname{Pr}$ and $N d$ systems has verified the existence of the $\mathrm{M}_{3} \mathrm{H}_{7}$ phase. [20]

\section{CONCLUSIONS}

The primary conclusion of this study is that two stability regimes exist in the Pu-H system. A metastable $\mathrm{CaF}_{2}$-anti- $\mathrm{Fe}_{3} \mathrm{Al}$-type solid solution formed by reaction of $\mathrm{Pu}$ and $\mathrm{H}_{2}$ or $\mathrm{PuH}_{2}$ and $\mathrm{H}_{2}$ at low temperatures. Solution of hydrogen in the phase is nearly ideal; cubic $\mathrm{PuH}_{3.0}$ can be prepared at $25^{\circ} \mathrm{C}$ and $25 \mathrm{~atm}$ pressure. A regime of ordered (stable) $\mathrm{CaF}_{2}$-related hydrides and a hexagonal $\mathrm{LaF}_{3}$-type $\mathrm{PuH}_{3-z}$ phase is attained at moderate pressures and temperatures $\geq 400^{\circ} \mathrm{C}$. The effect of temperature is dramatic because ordering can occur only if sufficient kinetic energy is available. The preparation of hexagonal $\mathrm{PuH}_{3-z}$ is especially temperature sensitive because the metal atoms 
must undergo a $\operatorname{ccp}$ to hcp transition.

An understanding of the stability differences of products formed in the two regimes is essential for interpreting the reactivity differences described by Bowersox. [7] The relative stabilities of hexagonal and cubic hydrides are demonstrated by their respective equilibrium pressures ( $0.03 \mathrm{vs} 25 \mathrm{~atm}$ ) at $25^{\circ} \mathrm{C}$. The relatively low pyrophoricity of the hexagonal phase is attributed to its lower equilibrium pressure.

Although substantial insight has been gained into the equilibrium behavior of the Pu-H system, the results have revealed several avenues which need investigation. Efforts to define the equilibria, thermodynamics, structural chemistry and kinetics of the ordered hydride phases are in progress.

\section{ACKNOWLEDGEMENT}

This work was performed under U. S. Department of Energy Contract DE-ACO4-76DP03533.

\section{REFERENCES}

[1] J. M. Haschke and J. L. Stakebake, Rare Earths in Science and Technology: Proceedings of the Fourteenth Rare Earth Research Conference, Plenum Publishing Co, New York (1980) in press.

[2] I. B. Johns, USAEC Report MDDC-717 (1944) 8pp.

[3] R. N. R. Mulford and G. E. Sturdy, J. Amer. Chem. Soc., 77 (1955) 3449.

[4] R. N. R. Mulford and G. E. Sturdy, J. Amer. Chem. Soc., 78 (1956) 3897.

[5] B. J. McDonald and J. B. Fardon, J. Chem. Soc., 1956 (1956) 781.

[6] T. Muromura, T. Yahata, K. Ouchi and M. Is ki, J. Inorg. Nucl. Chem, 34 (1972) 171.

[7] D. F. Bowersox, USAEC Report, LA-5515-MS (1974) $10 \mathrm{pp.}$

[8] D. F. Bowersox, ERDA Report, LA-6681-MS (1977) 7 pp.

[9] C. A. Alexander, Battelle Columbus Laboratory, private communication, (1979). [10] F. L. Oetting and D. R. Horrell, USAEC Report RF-2170 (1974) 6 pp. 
[11] M. I. Ivanov and N. S. Podolskaya, Russ. J. Phys. Chem., 45 (1971) 1682.

[12] C. A. Colmenares and C. Alexander, USAEC Report, UCID-16799 (1975) $10 \mathrm{pp}$.

[13] R. R. Dreisbach, PVT Relationships of Organic Compounds, Handbook Publishers, Sandusky, Ohio (1952).

[14] J. M. Haschke, Handbook on the Physics and Chemistry of Rare Earths, Vol. 4, North-Holland Publishing Co, , New York (1979) 89.

[15] 0. Greis, J. Solid State Chem., 24 (1978) 227.

[16] 0. Greis, Z. Anorg. Allgem. Chem., 441 (1978) 39.

[17] 0. Greis, Z. Anorg. Allgem. Chem., 430 (1977) 175.

[18] G. G. Libowitz and A. J. Maeland, Handbook on the Physics and Chemistry of Rare Earths, Vol. 3, North-Holland Publ ishing Co., New York (1979) 299.

[19] H. Müller, P. Knappe, and 0. Greis, Institut für Physikalische Chemie der Universität Münster, Vol. 1, Münster, Germany (1979).

[20] 0. Greis, Mineralogisch-Petrographisches Institut der Universität, Heidelberg, Germany, private communication (1979). 
Figure 1. $\log P\left(\mathrm{H}_{2}\right.$, Torr $)$ vs $1 / T$ data for cubic $\mathrm{PuH}_{\mathrm{X}}$ along constant composition sections. (The numerical constants $A$ and $B$ for $\log P=A-B / T$ are $l$ isted for various values of $X$ in the range $1.9 \leq X \leq 2.9$; values for the dasiled 7 ine at $x=1.9$ are from Ref. 1.)

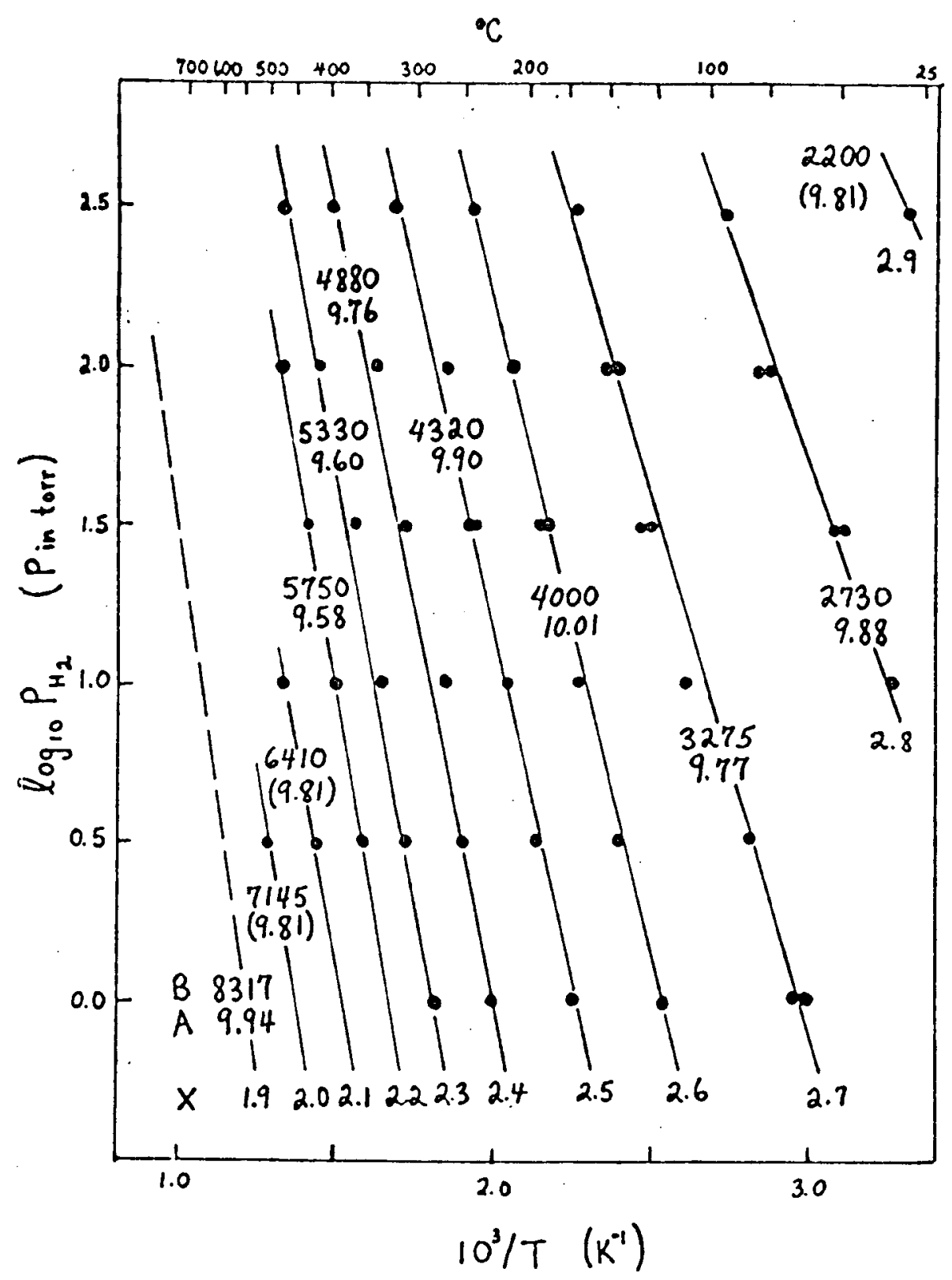


Figure 2. Correlation of the hydriding rates, $R$, and the gas phase temperature with composition, $x$, and with the phase diagram of the lanthanide fluorides (cf. Refs. 15-17).

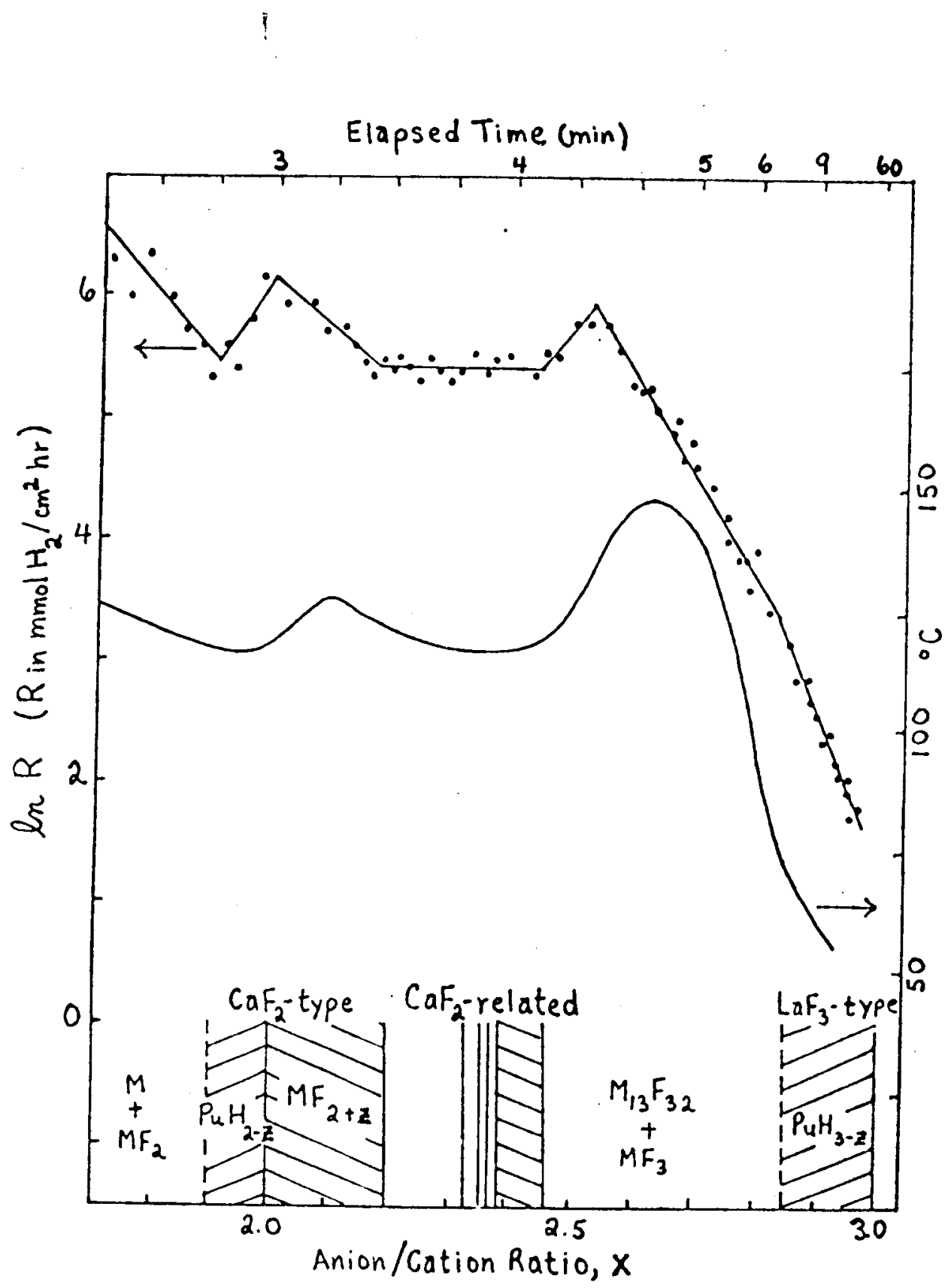

